\title{
Structure and properties of CoCrFeNix multi-principal element alloys from $a b$ initio calculations
}

Cite as: J. Appl. Phys. 127, 145102 (2020); https://doi.org/10.1063/1.5142239

Submitted: 11 December 2019 . Accepted: 17 March 2020 . Published Online: 10 April 2020

Natalia E. Koval (D), Joseba Iñaki Juaristi (D), Ricardo Díez Muiño (D), and Maite Alducin (D)

\section{COLLECTIONS}

F This paper was selected as Featured
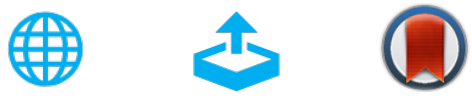

\section{ARTICLES YOU MAY BE INTERESTED IN}

Atomic simulation of interaction mechanism between dislocation and amorphous phase in dual-phase crystalline/amorphous $\mathrm{Mg} / \mathrm{MgAl}$ alloys

Journal of Applied Physics 127, 135105 (2020); https://doi.org/10.1063/1.5143721

Impact of transverse and vertical gate electric field on vibrational and electronic properties of $\mathrm{MoS}_{2}$

Journal of Applied Physics 127, 145101 (2020); https://doi.org/10.1063/1.5131845

Effect of valence electron concentration on stability of fcc or bcc phase in high entropy alloys Journal of Applied Physics 109, 103505 (2011); https://doi.org/10.1063/1.3587228

\section{Lock-in Amplifiers up to 600 $\mathrm{MHz}$}
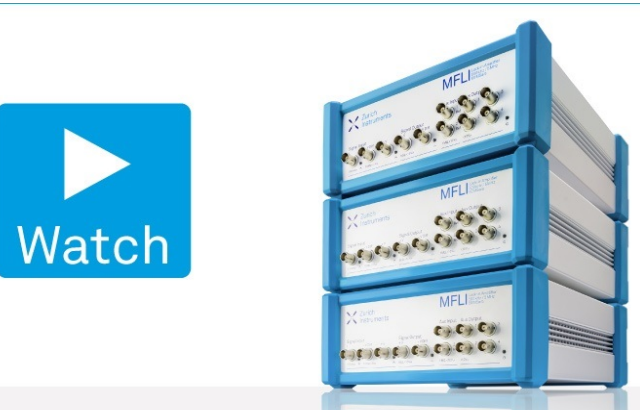


\title{
Structure and properties of CoCrFeNix multi-principal element alloys from $a b$ initio calculations
}

Cite as: J. Appl. Phys. 127, 145102 (2020); doi: 10.1063/1.5142239

Submitted: 11 December 2019 - Accepted: 17 March 2020 .

Published Online: 10 April 2020

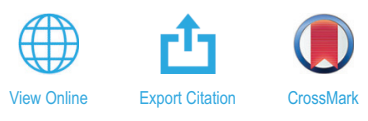

Natalia E. Koval, ${ }^{1,2,3, a)}$ (D) Joseba Iñaki Juaristi, ${ }^{1,2,4, b)}$ (D) Ricardo Díez Muiño, ${ }^{1,2, c)}$ (iD and Maite Alducin ${ }^{1,2, d)}$ (D)

\begin{abstract}
AFFILIATIONS
${ }^{7}$ Donostia International Physics Center DIPC, Paseo Manuel de Lardizabal 4, 20018 Donostia-San Sebastián, Spain

${ }^{2}$ Centro de Física de Materiales CFM/MPC (CSIC-UPV/EHU), Paseo Manuel de Lardizabal 5, 20018 Donostia-San Sebastián, Spain

${ }^{3}$ CIC nanoGUNE, Tolosa Hiribidea 76, 20018 Donostia-San Sebastián, Spain

${ }^{4}$ Departamento de Física de Materiales, Facultad de Químicas (UPV/EHU), Apartado 1072, 20080 Donostia-San Sebastián, Spain
\end{abstract}

\author{
a) Author to whom correspondence should be addressed: natalia_koval@ehu.eus \\ ${ }^{\text {b)} E l e c t r o n i c ~ m a i l: ~ j o s e b a i n a k i . j u a r i s t i @ e h u . e u s ~}$ \\ ${ }^{c)}$ Electronic mail: $r d m @ e h u . e u s$ \\ ${ }^{d)}$ Electronic mail: maite.alducin@ehu.eus
}

\begin{abstract}
Using density functional theory combined with an evolutionary algorithm for crystal structure prediction, we study the elastic and electronic properties of various multi-principal element alloys that are based on $\mathrm{CoCrFeNi}$. In total, nine quinary and one senary CoCrFeNiX $(\mathrm{X}=\mathrm{Ti}$, $\mathrm{V}$, $\mathrm{Mn}, \mathrm{MnV}, \mathrm{Cu}, \mathrm{Zr}, \mathrm{Nb}, \mathrm{Mo}, \mathrm{Al}, \mathrm{Al}_{2}$ ) alloys are studied along with the base CoCrFeNi alloy. The aim of the current study is twofold. First, we test and confirm the ability of the presented methodology to predict the crystal structure of the multi-principal element alloys based on Co, Cr, $\mathrm{Fe}$, and $\mathrm{Ni}$ elements. Second, we calculate and compare the elastic properties of the CoCrFeNiX alloys, as well as their electronic properties, in an attempt to establish possible correlations between them. Taking CoCrFeNi as the reference alloy, our first-principles calculations of various elastic moduli (bulk, Young, and shear moduli) show that only the bulk moduli of the alloys with $\mathrm{Cu}$, Mo, or $\mathrm{Nb}$ (in this order) are expected to be larger. Furthermore, our comparative analysis of the CoCrFeNiX alloys containing partially filled $3 d$ and $4 d$ elements shows that the filling of the $d$-shell causes a general increase in all the elastic moduli. The only exception is the decreasing behavior of the bulk modulus in the case of alloys with partially filled $3 d$ elements.
\end{abstract}

Published under license by AIP Publishing. https://doi.org/10.1063/1.5142239

\section{INTRODUCTION}

Multi-principal element alloys (MPEAs), also known as highentropy alloys (HEAs) or complex concentrated alloys (CCAs), ${ }^{1}$ are a new class of metallic alloys that have gained an increasing interest from both theoretical and experimental perspectives in recent years ${ }^{2}$ due to their promising mechanical properties, such as low weight, high strength, high corrosion resistance, etc. ${ }^{3-8}$ Unlike conventional alloys, MPEAs are composed of five or more metallic elements in equiatomic or nearly equiatomic proportions. The high configurational entropy, achieved by adding more alloying elements, was believed to play an important role in the stabilization of single-phase solid solutions with simple crystal structures, mostly body-centered cubic (BCC) and face-centered cubic (FCC), and less often hexagonal closed-packed (HCP). ${ }^{6}$ In practice, however, many MPEAs have multi-phase structures. ${ }^{9}$ The equiatomic $\mathrm{CuCoNiCrAlFe}^{10}$ and $\mathrm{CoCrFeNiMn}{ }^{11}$ alloys were the first singlephase MPEAs reported in the literature. The equiatomic CoCrFeNiMn alloy is now known as Cantor's alloy, and it became the model system for MPEA studies along with a more simple quaternary single-phase $\mathrm{CoCrFeNi}$ alloy.

Experimental studies of the CoCrFeNi-family MPEAs are extensive $^{12-43}$ but mostly focus on the Cantor alloy. In contrast, the number of theoretical studies of this MPEA family is limited so far $^{42,44-51}$ and also mainly studies the $\mathrm{CoCrFeNi}$, CoCrFeNiMn, 
and $\mathrm{CoCrFeNiAl}{ }_{x}$ alloys. In order to reduce the gap between the theoretical and experimental works, here we present a systematic $a b$ initio study of the structure and elastic properties of $\mathrm{CoCrFeNi}$, CoCrFeNiMn (Cantor alloy), and CoCrFeNiX (X = Ti, V, MnV, $\mathrm{Cu}, \mathrm{Zr}, \mathrm{Nb}, \mathrm{Mo}, \mathrm{Al}, \mathrm{Al}_{2}$ ) MPEAs, totaling 11 alloys for which the experimental structures are known. Our selection of $\mathrm{X}$ elements is double motivated. Together with the experimental data, the existing theoretical works on the $\mathrm{Cu}$ and $\mathrm{Al}$-containing alloys will serve us to test our methodology. In particular, our results for the elastic moduli are compared with those obtained by other common theoretical models. ${ }^{49}$ The general good prediction of the experimental crystal structures and the similar values of the elastic constants support the applicability of the $a b$ initio-based evolutionary methods. Our second motivation is to investigate the effect of adding $3 d(\mathrm{Ti}, \mathrm{V}, \mathrm{Mn})$ and $4 d(\mathrm{Zr}, \mathrm{Nb}, \mathrm{Mo})$ metals to the base $\mathrm{CoCrFeNi}$ alloy in an attempt to correlate the chemical composition and the elastic properties. To this aim, we perform an analysis of the electronic density and the bonding character of the electronic density of states of these alloys.

Modeling the structure of a MPEA is not a trivial task. Currently, the two most widely used methodologies for the theoretical simulation of the structure of disordered alloys are the coherent potential approximation $(\mathrm{CPA})^{52,53}$ and the special quasirandom structures (SQS) approximation. ${ }^{54,55}$ Both CPA and SQS methods require a prior knowledge of the crystal lattice type, thus, the predictiveness of these models must be based on some additional calculations, as, for example, the calculation of formation enthalpy. The SQS method is usually combined with DFT calculations of energy. The CPA method is commonly used together with the exact muffin-tin orbitals (EMTOs) method. ${ }^{47,49-51,56-58}$

In this work, we use a different approach to predict the alloy's structures. The method is based on Darwinian evolution and is implemented in the Universal Structure Predictor: Evolutionary Xtallography (USPEX) code. ${ }^{59-61}$ The evolutionary algorithm is combined with DFT calculations to find the most stable structure for a given chemical composition. The advantage of this method is that it does not require a prior knowledge of experimental parameters, such as crystal symmetry or lattice constant. The crystal structure is thus obtained from first principles. The USPEX method has been successfully applied to predict the structure of nanoparticles, polymers, 2D-crystals, surfaces, and interfaces at different temperature and pressure conditions. ${ }^{62}$ Recently, this method has proved to be useful in predicting the structure of MPEAs. ${ }^{63}$ Another evolutionary design strategy has also been recently applied to the search of strong and stable MPEAs. ${ }^{64}$ Here, we further test the ability of these kind of methods in predicting the crystal structure by comparing our new results for the CoCrFeNi-based MPEAs with the results from other methodologies, such as EMTO-CPA ${ }^{47,49-51,56-58}$ and SQS-DFT, ${ }^{50}$ as well as with existing experimental data. ${ }^{14,20,29,50,65-75}$

The article is organized as follows: in Sec. II, we briefly describe the evolutionary algorithm implemented in the USPEX code and the details of the DFT calculations of the elastic properties. The results are discussed in Sec. III. First, we show the results for the structure of the studied alloys and compare the obtained crystal lattice type as well as the lattice constants and formation energies to experiments. We then continue the discussion by analyzing the elastic properties and anisotropy of the CoCrFeNiX MPEAs. We end Sec. III with the analysis of the electronic and bonding properties of the alloys. The conclusions are summarized in Sec. IV.

\section{COMPUTATIONAL METHODS}

\section{A. Evolutionary algorithm for crystal structure prediction}

The evolutionary algorithm is based on the creation of generations of structures for a given composition and on the survival of the most stable structures in each generation. ${ }^{59}$ The only input parameter for the evolutionary search is the number of atoms of each species. The USPEX code then constructs the atomic structures in the first generation, using a random number generator, and in all subsequent generations, using evolutionary techniques, such as heredity (new structure from two "parenting" structures), permutation (exchange positions of atoms of different types), etc. The energy of each structure is calculated using an external solver. In this work, we use the Vienna $a b$ initio simulation package $(\text { VASP })^{76,77}$ to obtain all the energies at the DFT level within the generalized gradient approximation of Perdew-Burke-Ernzerhof $(\mathrm{PBE})^{78}$ to the exchange-correlation functional. The electron-core interaction is treated with the projector augmented-wave (PAW) method, ${ }^{79}$ using the implementation provided and developed for VASP. ${ }^{80}$ More details of the methodology used in this work are thoroughly described in our previous work. ${ }^{63}$

The number of atoms in the unit cell for all the studied alloys is $2 N$, where $N$ is the number of elements in the alloy. The exception is the base CoCrFeNi alloy that we use to test the importance of the unit cell size. In this case, two additional structures, containing $N$ and $4 N$ atoms in the unit cell, respectively, are calculated. As discussed below, the increase of the unit cell size only slightly improves the results as compared to experiments, while significantly increases the computational cost of the calculations.

\section{B. Bulk modulus from the equilibrium volume}

In some theoretical works to which we compare our results, the bulk modulus is derived by combining the equilibrium volume calculation and the equation of state. For this reason, we calculate the bulk modulus $B$ of the CoCrFeNi-based alloys from the DFT-calculated equilibrium volume-energy curve. The method is based on the thermodynamic equation of state for a harmonic solid

$$
E(V)=E_{0}+\left.\frac{1}{2} \frac{\partial^{2} E}{\partial V^{2}}\right|_{V_{0}}\left(V-V_{0}\right)^{2}
$$

combined with the thermodynamic relations

$$
P=-\left(\frac{\partial E}{\partial V}\right)_{S}, \quad B=-V\left(\frac{\partial P}{\partial V}\right)_{T},
$$

where $V$ is the volume, $P$ is the pressure, $E$ is the energy, and $B$ is the bulk modulus. Combining the two relations in Eq. (2), the 
equilibrium bulk modulus can be obtained as

$$
B_{0}=\left.V_{0} \frac{\partial^{2} E}{\partial V^{2}}\right|_{V_{0}} .
$$

Thus, the equilibrium energy $E_{0}$, volume $V_{0}$, and bulk modulus can be obtained by fitting the DFT energy vs volume results into the equation of state [Eq. (1)].

Alternatively, the bulk modulus, as well as other polycrystalline elastic moduli (shear and Young's modulus) can be calculated from the stress-strain relation as explained in Subsection II C. Both methods are expected to give similar bulk modulus for an isotropic system.

\section{Calculation of the elastic constants}

The elastic properties of the alloys are studied by the stressstrain approach of Le Page and Saxe, as implemented in the VASP package. $^{81}$ This approach is based on the Hooke's law, which describes the linear dependence of the stress components $\sigma_{i}$ $(i=1,6)$ and the small strain $\epsilon_{j}(j=1,6)$ applied to a relaxed crystal, $^{82,83}$

$$
\sigma_{i}=\sum_{j=1,6} c_{i j} \epsilon_{j}
$$

Here, $c_{i j}$ are the single-crystal elastic constants of the material, which are represented by a $6 \times 6$ tensor. The total elastic tensor is obtained by performing six finite distortions of the lattice.

For the system with cubic symmetry there are only three independent elastic constants: $c_{11}, c_{12}$, and $c_{44}{ }^{84}$ In our case, since the structures deviate slightly from a perfect cubic structure due to the different bond lengths of the constituent elements, there are nine non-identical elastic constants: $c_{11}, c_{12}, c_{13}, c_{23}, c_{22}, c_{33}, c_{44}, c_{55}$, and $c_{66}$. In order to obtain the cubic elastic constants of our disordered BCC structures, we follow a standard averaging scheme, ${ }^{85,86}$

$$
\begin{aligned}
& C_{11}=\left(c_{11}+c_{22}+c_{33}\right) / 3, \\
& C_{12}=\left(c_{12}+c_{13}+c_{23}\right) / 3, \\
& C_{44}=\left(c_{44}+c_{55}+c_{66}\right) / 3 .
\end{aligned}
$$

From the calculated single crystal elastic constants, we can obtain the polycrystalline elastic moduli of the system, such as the bulk modulus $B$, shear modulus $G$, Young's modulus $E$, and Poisson's ratio $v$, using the Voigt ${ }^{87}$ and Reuss ${ }^{88}$ approximations, which give an average of the single-crystal values over all orientations. ${ }^{89}$ The Voigt average is calculated assuming uniform strain throughout the material, while the Reuss average assumes uniform stress. ${ }^{90}$ The bulk modulus is the same in both approximations for an isotropic system,

$$
B=\left(C_{11}+2 C_{12}\right) / 3 \text {. }
$$

For the shear modulus, Reuss's scheme represents the lower limit, while Voigt's scheme represents the upper limit,

$$
G_{R}=\frac{5\left(C_{11}-C_{12}\right) C_{44}}{4 C_{44}+3\left(C_{11}-C_{12}\right)}, \quad G_{V}=\frac{\left(C_{11}-C_{12}+3 C_{44}\right)}{5} .
$$

Hill's mean value is then calculated as ${ }^{91}$

$$
G=\left(G_{V}+G_{R}\right) / 2 .
$$

Young's modulus $E$ and Poisson's ratio $v$ can be obtained from the bulk and shear moduli as

$$
E=\frac{9 B G}{3 B+G}, \quad v=\frac{3 B-2 G}{2(3 B+G)} .
$$

The elastic anisotropy of the system can be characterized by the Zener ratio $A_{Z}=2 C_{44} /\left(C_{11}-C_{12}\right),{ }^{92}$ which equals 1 for an elastically isotropic material. Another measure of the anisotropy is the ratio $A_{G_{V R}}=\left(G_{V}-G_{R}\right) /\left(G_{V}+G_{R}\right)$, which approaches zero for elastically isotropic materials, meaning that both Voigt and Reuss approximations give similar results.

\section{RESULTS AND DISCUSSION}

\section{A. Structure of CoCrFeNiX MPEAs}

An empirical parameter used to predict the single-phase solid solution formation is the mean square deviation of the atomic radius (or atomic mismatch parameter),

$$
\delta(\%)=100 \sqrt{\sum_{i=1}^{n} c_{i}\left(1-r_{i} / \bar{r}\right)^{2}}
$$

where $\bar{r}=\sum_{i=1}^{n} c_{i} r_{i}$ is an average radius, $c_{i}$ and $r_{i}$ are the atomic fraction and atomic radius of the $i$ th element, respectively, ${ }^{14,93}$ and $n$ is the total number of chemical elements in the alloy. It has been proposed that a single-phase solid solution MPEA can be formed if the atomic mismatch parameter $\delta$ is smaller than $6.6 \% .{ }^{14}$ A slightly different criterion suggested by Guo et al. ${ }^{93}$ implies that $\delta$ and the mixing enthalpy, $\Delta H_{\text {mix }}$, simultaneously satisfy the conditions $\delta<8.5 \%$ and $-0.22 \leqslant \Delta H_{\text {mix }} \leq 0.07 \mathrm{eV} /$ atom. The mixing enthalpy is defined as the difference between the cohesive energy of the alloy, $E_{\text {coh }}^{\mathrm{MPEA}}$, and the weighted sum of the cohesive energies of the alloy components,

$$
\Delta H_{\mathrm{mix}}=E_{\mathrm{coh}}^{\mathrm{MPEA}}-\sum_{i=1}^{n} c_{i} E_{\mathrm{coh}}^{i},
$$

where $E_{\text {coh }}^{i}$ is the cohesive energy of the $i$ th component, respectively.

Our results for all the studied MPEAs are shown in Table together with existing experimental data. $\delta$ parameter is calculated using the values of $r_{i}$ from Kittel, ${ }^{82}$ while the cohesive energies defining the enthalpy of mixing are calculated with spin-polarized DFT-PBE. Overall, the agreement between the calculated and experimental $\Delta H_{\mathrm{mix}}$ is good. The sign is well reproduced by our DFT-PBE calculations (except for the CoCrFeNiMo alloy).

Taking into account both $\delta$ parameter and the enthalpy of mixing, listed in Table I, all the alloys except $\mathrm{CoCrFeNiZr}$ and 
TABLE I. Atomic mismatch parameter $\delta(\%)$, calculated mixing enthalpy $\Delta H_{\text {mix }}(\mathrm{eV} /$ atom), and experimental mixing enthalpy $\Delta H_{\text {mix }}^{\exp }$ (eV/atom). The last column shows whether the empirical parameters predict the experimental single-phase and multiphase formation correctly (+) or not (-).

\begin{tabular}{lcccc}
\hline \hline MPEA & $\delta$ & $\Delta H_{\text {mix }}$ & $\Delta H_{\text {mix }}^{\text {exp }}$ & Str. predict. \\
\hline CoCrFeNi & 1.03 & -0.017 & $-0.039^{17}$ & + \\
CoCrFeNiTi & 6.13 & -0.116 & $-0.169^{65}$ & + \\
CoCrFeNiV & 2.88 & -0.075 & $-0.092^{65}$ & + \\
CoCrFeNiMn & 0.92 & -0.039 & $-0.044^{68}$ & + \\
CoCrFeNiMnV & 2.70 & -0.051 & $-0.079^{68}$ & - \\
CoCrFeNiCu & 1.07 & 0.050 & $0.034^{65}$ & + \\
CoCrFeNiZr & 10.19 & -0.131 & $-0.235^{94}$ & + \\
CoCrFeNiNb & 6.43 & -0.057 & $-0.156^{95}$ & - \\
CoCrFeNiMo & 4.36 & 0.044 & $-0.048^{94}$ & - \\
CoCrFeNiAl & 5.25 & -0.164 & $-0.129^{65}$ & + \\
CoCrFeNiAl & 6.04 & -0.353 & $-0.160^{96}$ & - \\
\hline \hline
\end{tabular}

$\mathrm{CoCrFeNiAl}_{2}$ should form single-phase solid solutions. The last column of Table I shows with "+" and "-" signs whether the empirical prediction of the single-phase or multi-phase formation using $\delta$ and $\Delta H_{\text {mix }}$ agrees or not with the experimental observations. In most of the cases, the prediction is correct according to the experimental data we could find (see Table II). Considering that these are empirical criteria, the prediction works quite well. Tsai et al. ${ }^{94}$ argue that incorrect predictions can be due to the fact that near-zero mixing enthalpy and small atomic size difference are only the necessary conditions but not the sufficient ones for the formation of the solid solution. The authors state that some intermetallic compounds also can have near-zero enthalpy of mixing and small atomic size differences, thus being considered as solid-solution phases. Moreover, we have noticed that different authors find single-phase or multi-phase structures for the same alloy composition (for example, CoCrFeNiTi is single-phase in Ref. 66 and multi-phase in Ref. 65; similarly, $\mathrm{CoCrFeNiV}$ is single-phase in Ref. 65 and multi-phase in Refs. 16 and 29). Thus, we can consider that the "-" signs in Table I do not strictly mean that the formation of the predicted phase is not possible.

In order to predict the crystal structure of an MPEA, another empirical parameter is often used, namely, the valence electron concentration (VEC) ${ }^{97}$ The average VEC of an alloy is calculated from the VECs of all constituent elements as VEC $=\sum_{i} c_{i}(\mathrm{VEC})_{i}$, where $c_{i}$ and (VEC) ${ }_{i}$ are the atomic fraction and the number of valence electrons (including outer $d$-electrons) of the $i$ th element, respectively. Typically, the FCC phase is found to be stable for alloys with $\mathrm{VEC} \geqslant 8$, while the BCC phase is stable at values $\mathrm{VEC}<6.87$. The intermediate values of $6.87<\mathrm{VEC}<8$ indicate the formation of more than one phase.

The VEC parameter for all the studied CoCrFeNiX alloys is listed in Table II along with the structure type according to our evolutionary search and the experimental structures. In general, the VEC parameter correctly predicts the formation of single-phase FCC or BCC, or multi-phase alloys. For CoCrFeNiTi, CoCrFeNiV, and $\mathrm{CoCrFeNiAl}$ (three out of 11 alloys), the VEC parameter incorrectly predicts the multi-phase formation, since experimentally these three alloys were observed to form single-phase solid solutions.

As for our single-phase calculations, the structures found by the DFT-based evolutionary algorithm agree with experiments for single-phase alloys. The main (solid solution) phase of the multiphase alloys is also predicted correctly by the evolutionary search. The only exceptions are the two alloys with the highest value of $\delta$ parameter, namely, CoCrFeNiZr $(\delta=10.19 \%)$ and $\mathrm{CoCrFeNiNb}$ $(\delta=6.43 \%)$, for which the evolutionary algorithm found disordered structures. Since the atomic size mismatch is very large, it is not possible to place the atoms in a cubic-like cell for these two alloys in our simulations. The large atomic size difference is also the reason why these two alloys do not form single-phase solid solutions in experiments. ${ }^{29}$

The average lattice constants of the studied MPEAs are also listed in Table II and compared with experimental lattice parameters when available. Since the lattice of the alloys is distorted due to

TABLE II. Comparison of the theoretical crystal structures predicted by the VEC parameter (value within parenthesis), the DFT-based single-phase evolutionary search (DFT-SP), and the experimental data. Corresponding DFT-SP average lattice constant a ( \pm standard deviation) and experimental lattice constant $a_{\mathrm{exp}}$. Experimental values extracted from multi-phase alloys are marked with $\left(^{*}\right)$ and refer to the main solid-solution phase of the alloy.

\begin{tabular}{|c|c|c|c|c|c|}
\hline MPEA & VEC & DFT-SP & Experiment $^{\mathrm{a}}$ & $a(\AA)$ & $a_{\exp }(\AA)$ \\
\hline $\mathrm{CoCrFeNi}$ & FCC (8.25) & FCC & SP-SS $(F C C)^{14,16}$ & $3.55 \pm 0.026$ & $3.568-3.577^{16,19,98}$ \\
\hline CoCrFeNiTi & interm (7.40) & FCC & SP-SS (FCC) ${ }^{66}$ & $3.65 \pm 0.14$ & $3.589^{66}$ \\
\hline $\mathrm{CoCrFeNiV}$ & interm (7.60) & FCC & SP-SS (FCC) ${ }^{65}$ & $3.62 \pm 0.12$ & $3.58^{11}$ \\
\hline CoCrFeNiMn & FCC (8.00) & FCC & SP-SS $(\mathrm{FCC})^{14,16}$ & $3.58 \pm 0.06$ & $3.602,{ }^{16} 3.592^{68}$ \\
\hline CoCrFeNiMnV & interm (7.50) & FCC & MP (FCC+Tetr) ${ }^{68}$ & $3.52 \pm 0.23$ & $3.603,{ }^{68} 3.612^{16}\left({ }^{*}\right)$ \\
\hline $\mathrm{CoCrFeNiCu}$ & FCC (8.80) & FCC & SP-SS $(\mathrm{FCC})^{14}$ & $3.57 \pm 0.085$ & $3.58,^{99} 3.588^{100}$ \\
\hline CoCrFeNiZr & interm (7.40) & disord & $\mathrm{MP}(\mathrm{IC}+\mathrm{BCC})^{29}$ & $\ldots$ & $\ldots$ \\
\hline $\mathrm{CoCrFeNiNb}$ & interm (7.60) & disord & $\mathrm{MP}(\mathrm{IC}+\mathrm{FCC})^{29}$ & $\ldots$ & 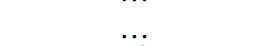 \\
\hline CoCrFeNiMo & interm (7.80) & FCC & MP $(\mathrm{IC}+\mathrm{FCC})^{29}$ & $3.63 \pm 0.13$ & $3.619^{\mathrm{b}}\left(^{*}\right)$ \\
\hline $\mathrm{CoCrFeNiAl}$ & interm (7.20) & BCC & SP-SS (BCC) $)^{14,102}$ & $2.57 \pm 0.26$ & $2.86,^{102} 2.88^{98}$ \\
\hline $\mathrm{CoCrFeNiAl}_{2}$ & BCC (6.50) & BCC & SP-SS (BCC) ${ }^{12,14}$ & $2.86 \pm 0.026$ & $2.887^{12,98}$ \\
\hline
\end{tabular}

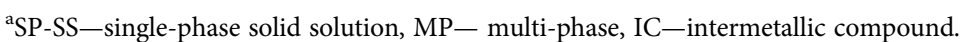

${ }^{\mathrm{b}} \mathrm{CoCrFeNiMo}{ }_{0.85}$ (Ref. 101). 


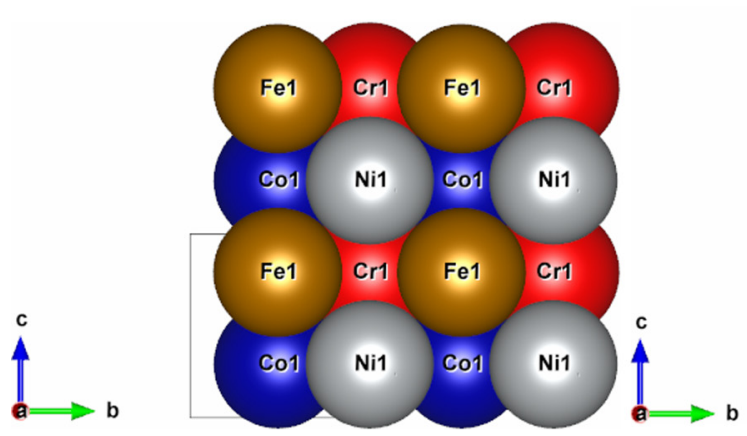

the atomic size mismatch of the different alloy components, we show the average lattice parameter and the standard deviation for each alloy. In the case of experimentally observed multi-phase alloys (CoCrFeNiMnV and CoCrFeNiMo), the value of $a_{\exp }$ in Table II corresponds to the lattice parameter of the main solid solution FCC phase of these alloys. In general, the agreement with experiments is very good, except for the CoCrFeNiAl alloy for which we find a slightly smaller lattice constant value than the experimental one.

\section{B. Elastic moduli}

We start the analysis by exploring the effect of the employed unit cell size on the calculated elastic properties. Namely, we perform calculations of the elastic constants $C_{i j}$ and corresponding elastic moduli (see Sec. II C) for the CoCrFeNi alloy with 4 and 16 $\left(\mathrm{Co}_{4} \mathrm{Cr}_{4} \mathrm{Fe}_{4} \mathrm{Ni}_{4}\right)$ atoms in the unit cell. The structures obtained by the evolutionary search for both unit cells are shown in Fig. 1. The atomic arrangement is different in these two alloys. However, the results in Table III show that the corresponding elastic moduli differ in less than $2 \%$ and that in both cases our values agree very well with the EMTO-CPA results. Thus, we can conclude that the elastic properties are not much influenced by the unit cell size employed in the calculations or by the particular atomic configuration. A similar result was already observed in the TiZrNbTaMo alloy $^{63}$ and also in two-component alloys, ${ }^{103}$ namely, that the elastic properties are not significantly affected by the atomic ordering but rather by the composition.

Table IV shows our results of the bulk modulus $B$ calculated for all the studied alloys by the two different methods explained in Sec. II, i.e., from the equation of state and from the elastic constants, together with the available theoretical data. The theoretical values of $B$ differ from one reference to another and are still very

TABLE III. Cell size effect on the elastic moduli of the CoCrFeNi alloy.

\begin{tabular}{lccccccc}
\hline \hline MPEA & $B$ & $G$ & $E$ & & & & \\
\hline $\mathrm{CoCrFeNi}$ & 204 & 118.6 & 298 & 0.256 & 1.71 & 0.049 & 1.91 \\
$\mathrm{Co}_{4} \mathrm{Cr}_{4} \mathrm{Fe}_{4} \mathrm{Ni}_{4}$ & 202 & 120.8 & 302 & 0.251 & 1.67 & 0.039 & 1.77 \\
EMTO-CPA $^{56}$ & 207 & 110 & 280 & 0.275 & 1.88 & 0.21 & 3.9 \\
\hline \hline
\end{tabular}

limited. Our results are in a reasonable agreement with other calculations. For most of the alloys, we get very similar values of the bulk modulus by both methods, as expected. The agreement between the two methods can be viewed as an indicator of the degree to which we can trust the results of our calculations. For the CoCrFeNiAl and $\mathrm{CoCrFeNiAl}_{2}$ alloys, the calculations using the EMTO-CPA method have shown that the bulk modulus decreases as the $\mathrm{Al}$ content increases (both, when calculated from the equation of state and from the single crystal elastic constants). ${ }^{49}$ In our case, the values of $B$ obtained from the equilibrium volume calculations show the same trend, but it is not the case for $B$ calculated from the elastic constants (Table IV). The lack of experimental data does not allow us to verify these results.

Young's and shear moduli, the Poisson ratio, and the anisotropy parameters obtained from the elastic constants $C_{i j}$ are listed in Table $\mathrm{V}$ and compared to experiments when possible. The quantity that is most often measured in experiments is the elastic (Young's) modulus. For the rest of elastic properties, the experimental data are very limited. Overall, the agreement with experiments is qualitative, not quantitative. The values for the CoCrFeNiMn alloy are in agreement with other calculations ${ }^{47,50,51}$ and also are in a reasonably good agreement with experimental results. ${ }^{67,69}$ Young's modulus of CoCrFeNiZr and $\mathrm{CoCrFeNiAl}$ also agree well with the experimental values. For $\mathrm{CoCrFeNiCu}$, however, the calculated

TABLE IV. Our theoretical bulk modulus of the CoCrFeNiX alloys obtained from the equilibrium volume, $B\left(V_{0}\right)$, and from the elastic constants, $B\left(C_{i j}\right)$ are compared to available theoretical data. All values are in $\mathrm{GPa}$.

\begin{tabular}{lccc}
\hline \hline MPEA & $B\left(\mathrm{~V}_{0}\right)$ & $B\left(C_{i j}\right)$ & $B$ (refs.) \\
\hline CoCrFeNi & 209 & 204.0 & $145-210^{7,50,56}$ \\
CoCrFeNiTi & 185 & 185.8 & $175^{56}$ \\
CoCrFeNiV & 169 & 170.2 & $\ldots$ \\
CoCrFeNiMn & 157 & 156.6 & $130-185^{7,50}$ \\
CoCrFeNiMnV & 177 & 193.7 & $\ldots$ \\
CoCrFeNiCu & 181 & 255.5 & $156.9^{7}$ \\
CoCrFeNiZr & 170 & 170.4 & $\ldots$ \\
CoCrFeNiNb & 228 & 228.6 & $\ldots$ \\
CoCrFeNiMo & 260 & 241.5 & $\ldots$ \\
CoCrFeNiAl & 173 & 154.1 & $183^{49}$ \\
CoCrFeNiAl & 167 & 205.3 & $159^{49}$ \\
\hline \hline
\end{tabular}


TABLE V. Shear $G(\mathrm{GPa})$ and Young's $E(\mathrm{GPa})$ moduli, Poisson's ratio $v$, Pugh's ratio $B / G$, elastic anisotropy $A_{G_{V R}}$, and Zener anisotropy ratio $A_{z}$ for the CoCrFeNiX alloys. Experimental data within parentheses (data extracted from multi-phase alloys are marked with an asterisk).

\begin{tabular}{lcccccc}
\hline \hline MPEA & $G\left(G_{\text {exp }}\right)$ & $E\left(E_{\text {exp }}\right)$ & $v\left(v_{\exp }\right)$ & $B / G$ & $\mathrm{~A}_{G_{V R}}$ & $\mathrm{~A}_{z}$ \\
\hline CoCrFeNi & 118.6 & $298\left(214^{\mathrm{a}}\right)$ & 0.26 & 1.71 & 0.049 & 1.91 \\
& $\left(86^{\mathrm{a}}\right)$ & & $\left(0.25^{\mathrm{a}}\right)$ & & & \\
CoCrFeNiTi & 92.3 & 237.6 & 0.29 & 2.01 & 0.013 & 1.38 \\
& & $\left(134.6^{\mathrm{b}}\right)$ & & & & \\
CoCrFeNiV & 101.2 & 253.4 & 0.25 & 1.68 & 0.049 & 1.91 \\
CoCrFeNiMn & 109.7 & 266.8 & 0.22 & 1.43 & 0.062 & 2.07 \\
& $\left(86^{67}\right)$ & $\left(215^{67}\right)$ & $\left(0.25^{67}\right)$ & & & \\
CoCrFeNiMnV & 77.5 & 205.1 & 0.32 & 2.50 & 0.14 & 3.06 \\
CoCrFeNiCu & 98.0 & 260.8 & 0.33 & 2.61 & 0.0004 & 1.06 \\
& & $\left(170^{71}\right)^{*}$ & & & & \\
CoCrFeNiZr & 69.8 & 185.1 & 0.32 & 2.44 & 0.0006 & 1.08 \\
CoCrFeNiNb & 85.3 & 227.7 & 0.33 & 2.68 & 0.0005 & 0.94 \\
CoCrFeNiMo & 105.5 & 276.3 & 0.31 & 2.29 & 0.005 & 1.88 \\
CoCrFeNiAl & 94.56 & 235.5 & 0.25 & 1.63 & 0.006 & 1.25 \\
CoCrFeNiAl & 95.4 & 247.8 & 0.30 & 2.15 & 0.0001 & 0.97 \\
\hline \hline
\end{tabular}

${ }^{\mathrm{a}}$ Room temperature. ${ }^{75}$

${ }^{\mathrm{b}}$ Room temperature. ${ }^{66}$

${ }^{c}$ Experimental data for $\mathrm{CoCrFeNiZr}_{0.5}$ at room temperature. ${ }^{74}$

$\mathrm{d}_{225} \pm 45 \mathrm{GPa}$ and $236 \pm 38 \mathrm{GPa}$ for different phases; ${ }^{72} 300,220$, and 160 GPa in Ref. 73 for three phases.

elastic modulus is much higher than the experimental value. A plausible reason is that the experimental measurements in Ref. 71 are done for the multi-phase structure, while in our calculations all the alloys are single phase. In the case of CoCrFeNiTi, the results disagree as well, although the experimental alloy is also single phase. The calculations by Tian et al. with EMTO-CPA method $^{56}$ showed a better agreement with the experimental $E$ for $\mathrm{CoCrFeNiTi}$; however, they obtained very high anisotropy ratios.

The values of the Pugh ratio, $B / G$, for the CoCrFeNiX alloys are also shown in Table $V$. The ratio $B / G$ is used as an indicator of the ductile-brittle behavior of materials. ${ }^{104}$ Ductile materials usually have values $B / G>1.75$, while brittle materials have values $B / G<1.75$. Poisson's ratio, $v$, can also be used to predict the brittle-ductile behavior. ${ }^{105}$ It has been shown that bulk metallic glasses with $v>0.31$ are ductile and that this parameter can also be applied to MPEAs.

The charts in Fig. 2 summarize the elastic moduli and Poisson's and Pugh's ratios for all the alloys studied in this work. The elastic properties of $\mathrm{CoCrFeNi}$ alloy change in a similar manner when a $3 d(\mathrm{Ti}, \mathrm{V}, \mathrm{Mn})$ or a $4 d(\mathrm{Zr}, \mathrm{Nb}, \mathrm{Mo})$ element is added into the alloy. Namely, the elastic moduli (E and G) increase when we move from $\mathrm{Ti}$ to $\mathrm{Mn}$ and from $\mathrm{Zr}$ to Mo, i.e., when the electronic d-shell is populated with more electrons. The increase of the elastic moduli also correlates with the decrease of the $\delta$ parameter for both groups of alloys. The only exception is the bulk modulus, which also increases for the $4 d$, but for the $3 d$ group the opposite trend is observed, i.e., B decreases when moving from $\mathrm{Ti}$ to $\mathrm{Mn}$. We analyze the electronic structure of the $3 d$ and $4 d$-group alloys in Sec. III D in order to gain insights into this difference.

Comparing the base alloy $\mathrm{CoCrFeNi}$ with the 5- and 6-element alloys, we observe that the bulk modulus of $\mathrm{CoCrFeNi}$ is increased by adding $\mathrm{Cu}, \mathrm{Nb}$, and $\mathrm{Mo}$. In contrast, the shear modulus is slightly reduced in all cases as compared to CoCrFeNi. Young's modulus is generally high for all the alloys (comparable or even higher than that of most steels ${ }^{106}$ ), which suggests that most of the CoCrFeNiX alloys are stiff. Again, the base alloy possess the highest Young's modulus.

Poisson's and Pugh's ratios are shown in the same panel of Fig. 2 as histograms and blue squares, respectively. The horizontal dashed line shows the brittle/ductile transition for both ratios. Most of the alloys have high enough $B / G$ to be considered ductile. However, taking into account both $v$ and $B / G$, the ductile alloys are CoCrFeNiMnV, CoCrFeNiCu, CoCrFeNiZr, CoCrFeNiNb, and CoCrFeNiMo. The behavior of Poisson's ratio and the Pugh ratio is consistent, i.e., both follow the same trend. Our ductile/brittle predictions for those single-phase HEAs that are also characterized in experiments are relatively good. Experimentally, both the $\mathrm{CoCrFeNi}$ and the Cantor (CoCrFeNiMn) solid-solution alloys are found to be ductile, being the former more ductile than the latter ${ }^{16}$-as also predicted by our calculations [both $v$ and (particularly) $B / G$ are lower for the Cantor alloy]. Also, the CoCrFeNiTi and CoCrFeNiCu alloys (both single-phase) are ductile according to experiments. ${ }^{66,99}$ Here the agreement with the theoretical predictions is partial since only the calculated $B / G$ ratio for $\mathrm{CoCrFeNiTi}$ agrees with the ductile character. Finally, experiments performed on $\mathrm{CoCrFeNiV}$, CoCrFeNiMnV, and CoCrFeNiAl showed that these alloys are brittle. ${ }^{16,73}$ However, the alloys used in these experiments are not single-phase but multiphase and the brittleness is associated with small fractions of $\sigma$-phases in the three alloys. Unfortunately, no information on ductility is provided for the single-phase $\mathrm{CoCrFeNiV}$ and $\mathrm{CoCrFeNiMnV}$ alloys in Refs. 14 and 65 that would be directly comparable to our results for the single-phase cases.

Figure 3 shows the dependence of the elastic moduli $B, G$, and $E$ on parameter $\delta$ for all the quinary equiatomic alloys studied in this work. The data are presented as symbols, and the best linear fit is shown with a line in all three panels. Although there is not any obvious dependence of the bulk modulus on $\delta$, in the case of both shear and Young's moduli, there is a tendency to lower values when the $\delta$ parameter increases. Similar behavior was observed for the AlCrFeNiTiX alloy family by Nong et al., ${ }^{107}$ where they also found that $B, G$, and $E$ decrease with higher $\delta$ and that the effect is much larger for $G$ and $E$ than for $B$. This is consistent with the fact that high $\delta$ values are associated with large lattice distortions in the alloys, which result in the lattice being less resistant to deformations.

\section{Elastic anisotropy}

Figure 4 shows three-dimensional plots of Young's modulus $E$ along [ $h k l]$ crystallographic directions ${ }^{108}$ for $\mathrm{CoCrFeNi}$ (the base alloy), CoCrFeNiMnV (the most anisotropic alloy), and CoCrFeNiZr (the most isotropic alloy) calculated and plotted with SC-EMA (Self-Consistent Calculations-Elasticity of Multi-phase Aggregates) 

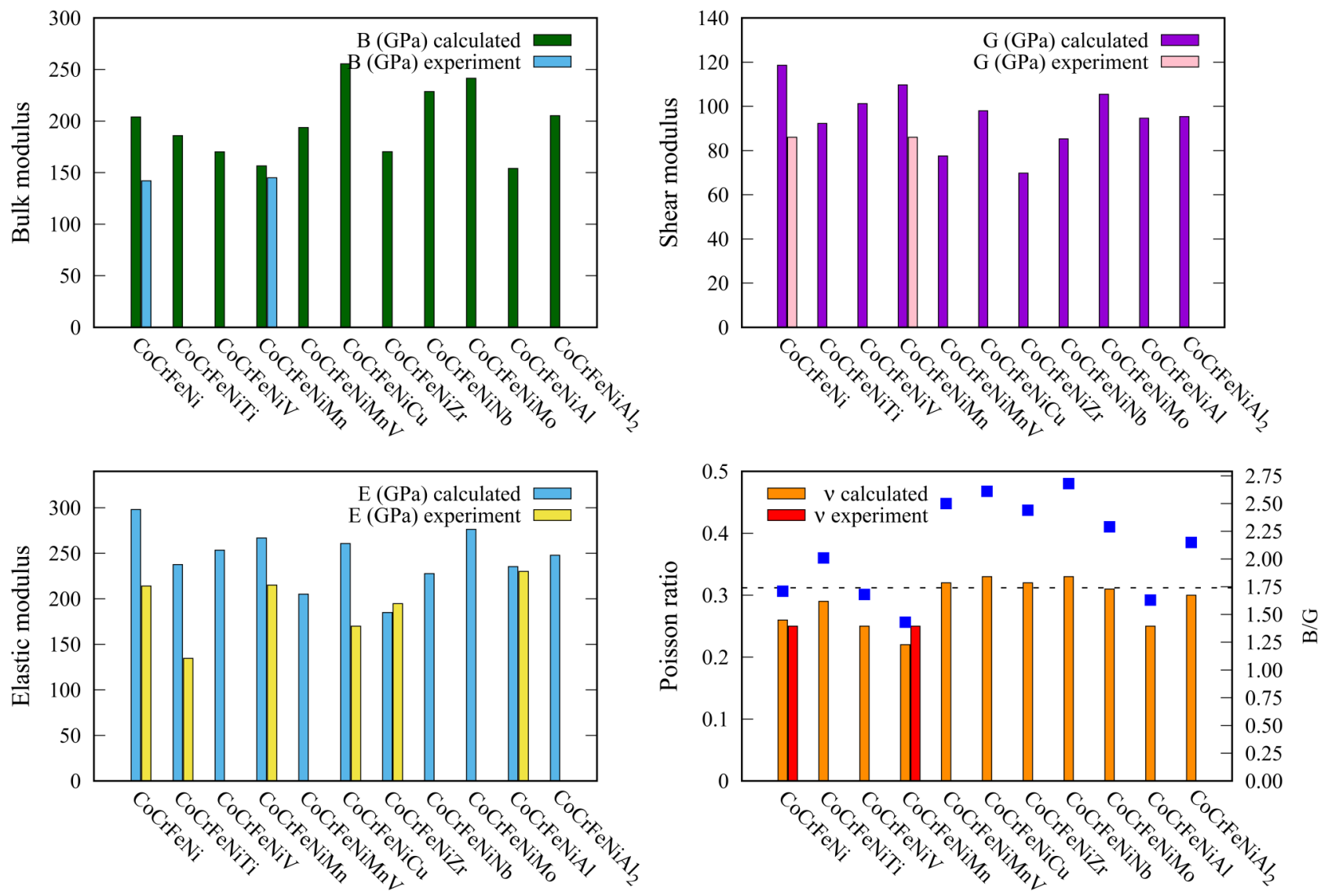

FIG. 2. Calculated bulk modulus $B(\mathrm{GPa})$, shear modulus $G(\mathrm{GPa})$, Young's modulus $E(\mathrm{GPa})$, and Poisson's ratio $v$ for all the studied alloys. Comparison with experiments is shown when available (references for $E, G$, and $v$ as in Table $\mathrm{V}$; experimental $B$ for the single-phase CoCrFeNi and CoCrFeNiMn alloys from Refs. 67 and 75 , respectively). The Pugh ratio $B / G$ is shown as blue squares together with Poisson's ratio with the scale on the right. Horizontal dashed line shows the brittle/ductile transition for both Poisson's and Pugh's ratios.

software $^{109-112}$ using our computed elastic constants. The values on both the color scale and the axes are Young's modulus in GPa. Young's modulus is considered to be more isotropic when the shape of the three-dimensional plot is closer to a sphere. The most isotropic elastic modulus is obtained for the CoCrFeNiZr alloy, while the most anisotropic shape is observed in CoCrFeNiMnV, which also shows the highest values of the anisotropy ratios $\mathrm{A}_{G_{V R}}$ and $\mathrm{A}_{z}$ in Table $\mathrm{V}$. In general, all the CoCrFeNiX alloys show certain directional dependence of elastic modulus $E$ (see the supplementary material for the direction-dependent Young's modulus of all the alloys). The orientation dependence of the elastic properties in MPEAs was also observed experimentally. ${ }^{113-116}$

The anisotropy in $E$ can somehow be correlated with the spatial distribution of the electron charge density, as we exemplify it next with CoCrFeNi [Fig. 4(a)]. Young's modulus along the [111] and [11ㅣ] directions is much higher than the one along the [100], [001] and [010] directions for this alloy. Figure 5 shows the projected charge density isosurfaces along the direction of maximum ([111]) and minimum ([010]) values of Young's modulus. Each projection is calculated as the sum of various $(h \mathrm{kl})$ slices of the electron density along the $[h k l]$ direction. The bonds between the atoms are stronger in the case of the projection along the direction [111] that corresponds to the maximum of Young's modulus, while the bonds are weaker in the case of the projection along the direction [001], along the minimum of Young's modulus as can be see from Fig. 5. This shows that the bonding strength between the atoms in different crystallographic directions significantly influences Young's modulus.

\section{Electronic properties and bonding}

In the following, we analyze whether a relation can be obtained between the electronic structure and elastic properties of the CoCrFeNiX alloys. With this aim, we calculate their density of states (DOS) and the crystal orbital Hamilton populations (COHP). We focus on the analysis of six alloys, three with $\mathrm{X}$ from the $3 d$ 

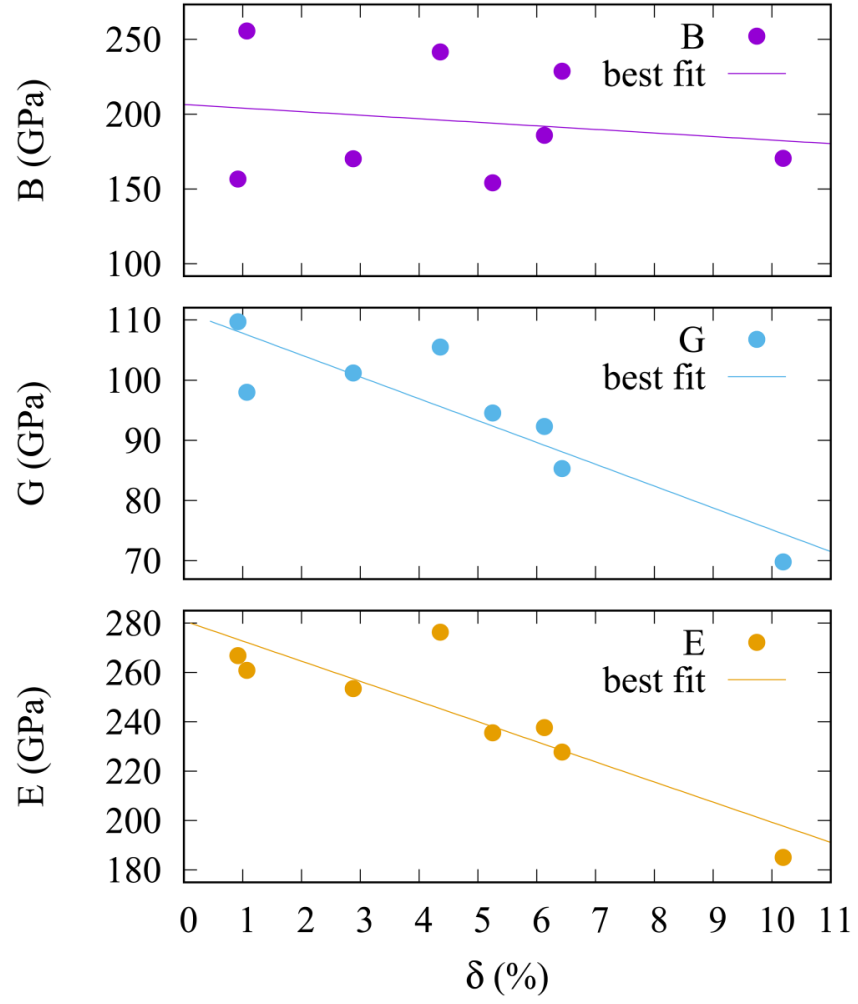

FIG. 3. Bulk modulus $B(\mathrm{GPa})$, shear modulus, $G(\mathrm{GPa})$, and Young's modulus $E(\mathrm{GPa})$ as a function of the atomic size mismatch parameter $\delta(\%)$ for all the equiatomic alloys containing five elements. The data are fitted to the linear equation $f(\delta)=m \delta+b$, where $f=B, G$, or $E$. The corresponding standard deviations of the regression for the fitting coefficients $m$ and $b$, respectively, are $216.1 \%$ and $13.79 \%(B), 20.2 \%$ and $3.832 \%(G)$, and $22.85 \%$ and $3.621 \%(E)$.

group $(\mathrm{X}=\mathrm{Ti}, \mathrm{V}, \mathrm{Mn})$ and three with $\mathrm{X}$ from the $4 d$ group $(\mathrm{X}=\mathrm{Zr}, \mathrm{Nb}, \mathrm{Mo})$. The total and partial (projection for each element) DOS for the rest of the alloys are shown in Figs. S1-S3 of the supplementary material.

Figure 6 shows the total (spin-up plus spin-down) DOS for six CoCrFeNiX alloys, with $\mathrm{X}=\mathrm{Ti}, \mathrm{V}$, and $\mathrm{Mn}$ (left plots) and $\mathrm{X}=\mathrm{Zr}, \mathrm{Nb}$, and Mo (right plots). For the $3 d$ group, all three alloys have a pronounced pseudogap close to the Fermi level which is usually considered as an indication of mechanical stability. On the contrary, the DOS for the $4 d$ group is almost flat at the Fermi level, showing no pseudogap. Interestingly, the $3 d$ group, i.e., the CoCrFeNiTi, CoCrFeNiV, and CoCrFeNiMn alloys form singlephase solid solutions, while the CoCrFeNiZr, CoCrFeNiNb, and $\mathrm{CoCrFeNiMo} \mathrm{crystallize} \mathrm{in} \mathrm{multi-phase} \mathrm{structures.}$

The crystal orbital Hamilton populations $(\mathrm{COHP})^{117}$ are calculated using the LOBSTER (Local Orbital Basis Suite Toward Electronic-Structure Reconstruction) $\operatorname{code}^{118-121}$ which enables chemical-bonding analysis based on the VASP output. For each pair of neighboring atoms, the interaction between the $\phi_{\mu}$ and $\phi_{v}$ orbitals, which are, respectively, centered at each atom, is described
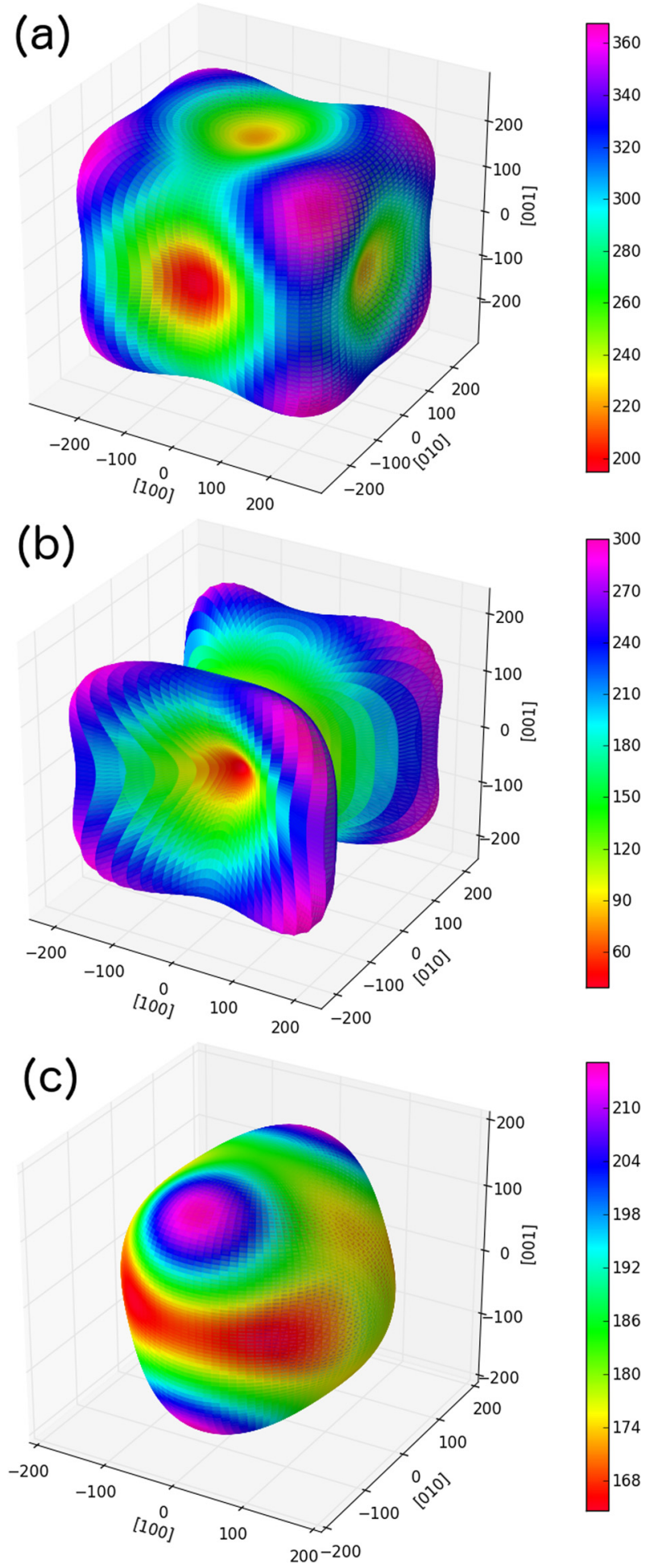

FIG. 4. Direction-dependent Young's modulus (in GPa) for (a) CoCrFeNi, (b) CoCrFeNiMnV, and (c) CoCrFeNiZr alloys. 


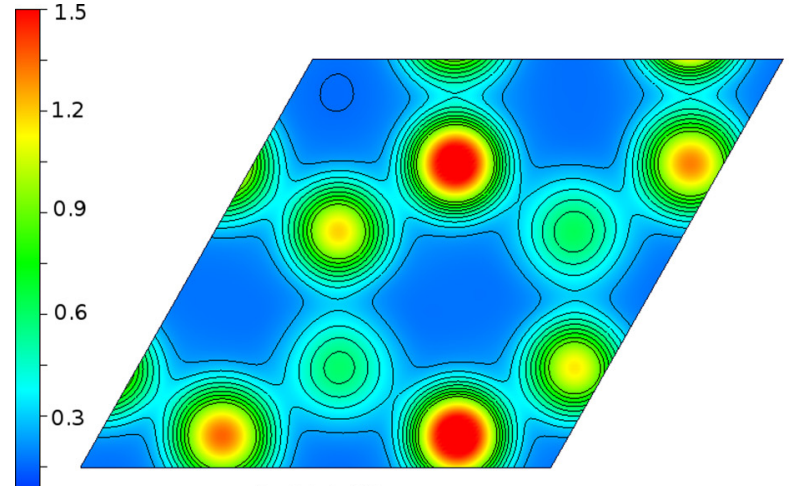

0.0

a) $[111]$

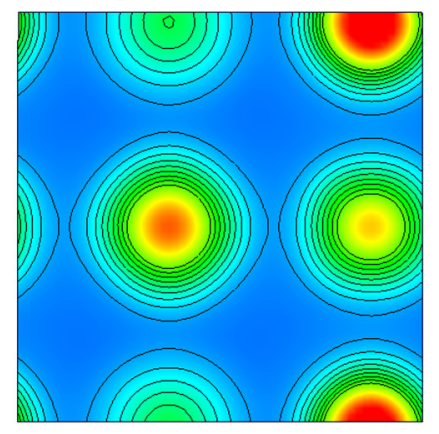

b) $[001]$
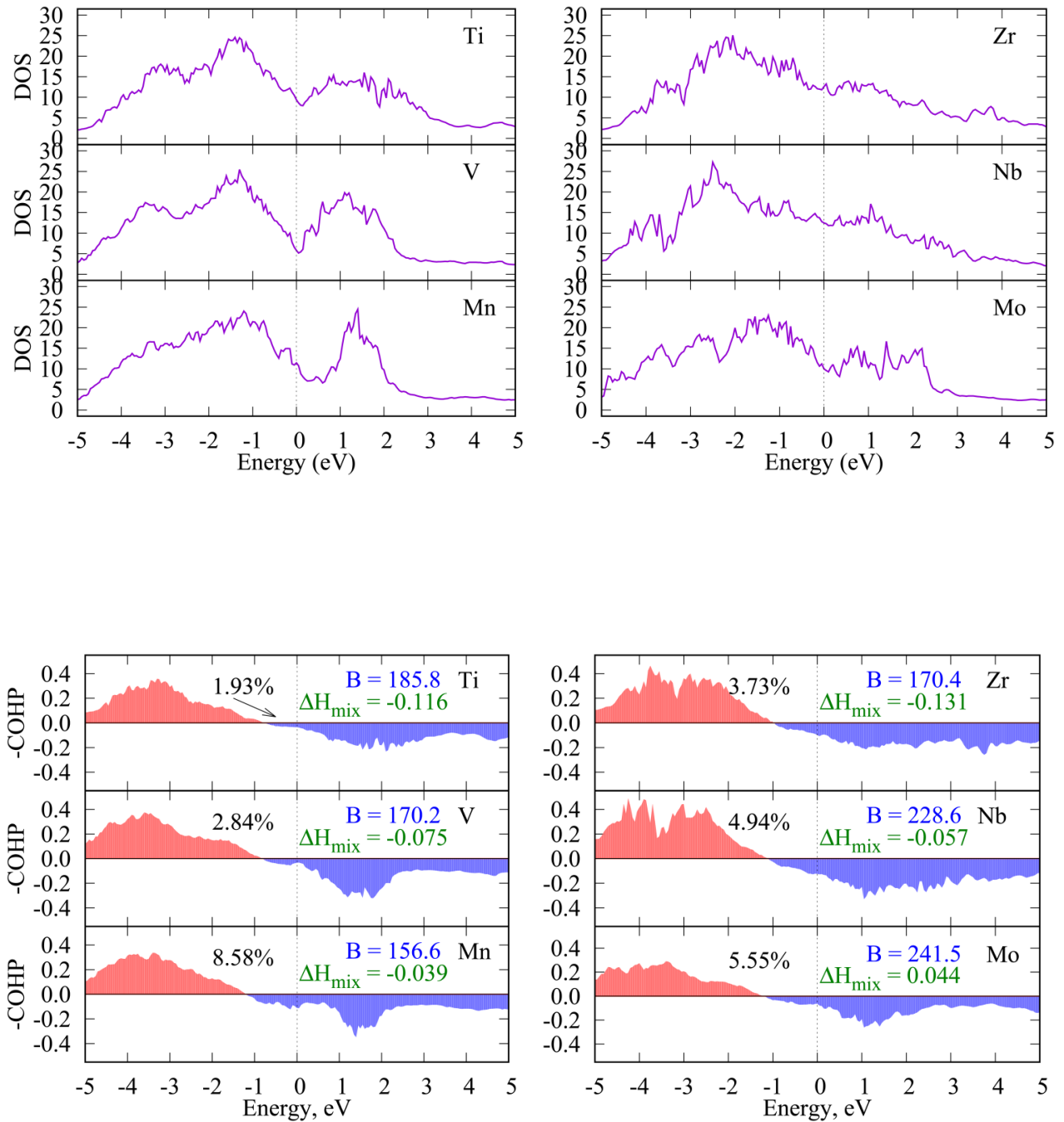

FIG. 5. Projected charge density isosurfaces for the CoCrFeNi alloy: (a) along the maximum of Young's modulus (crystallographic direction [111]) and (b) along the minimum of Young's modulus (crystallographic direction [001]). The color code shows the charge density in electrons $/ \AA^{3}$. The contour lines have an interval of 0.08 .

FIG. 6. Total DOS for CoCrFeNiX alloys. Left: $3 d$-elements; Right: $4 d$-elements.

FIG. 7. COHP for CoCrFeNiX alloys. Left: $3 d$-elements; Right: 4d-elements. Positive (red shade) and negative (blue shade) values correspond to bonding and antibonding states, respectively. The percentage of the antibonding part of the occupied area (blue area on the left of the vertical dashed line, showing the Fermi energy, $E_{F}=0$ ) is indicated on each plot. The values of the bulk modulus in $\mathrm{GPa}$ and the enthalpy of mixing in eV/atom are indicated on each plot in blue and green colors, respectively. 
by the Hamiltonian matrix element $H_{\mu v}=\left\langle\phi_{\mu}|\hat{H}| \phi_{v}\right\rangle \cdot{ }^{119}$ The multiplication of the Hamiltonian matrix elements by the corresponding DOS matrix serves as a quantitative measure of the bond strength. The product either lowers (bonding) or raises (antibonding) the band-structure energy. Thus, energy-resolved COHP plots allow distinguishing between bonding, nonbonding (no energetic effect), and antibonding contributions. ${ }^{119}$ We plot the -COHP values to represent the bonding by positive values and antibonding by negative values.

The resulting -COHPs are shown in Fig. 7 for the same alloys as in Fig. 6, and the values of the bulk modulus and enthalpy of mixing are indicated for each alloy. The transition from bonding to antibonding states lies below the Fermi energy for all the alloys, meaning that in all the alloys there are occupied antibonding states. The percentage of the occupied antibonding part is different for each alloy. Their values, which are calculated as the percentage of the blue area below the Fermi level from all the area below the Fermi level, are written in Fig. 7. Both in the case of $3 d$ or $4 d$ additional element, the percentage is larger when going from left to right in the periodic table (from top to bottom on the panels of Fig. 7). In principle, having more occupied antibonding states makes the system less stable. This is indeed what the corresponding increasing values of the mixing enthalpy $\Delta H_{\text {mix }}$ do suggest. Furthermore, one would also expect that the more stable structures were characterized by larger bulk modulus, as we actually observe for the CoCrFeNiX alloys, where $\mathrm{X}$ is a $3 d$ metal (note that the bulk modulus decreases when the percentage of the occupied antibonding states and $\Delta H_{\text {mix }}$ increase). A similar correlation between increasing values of $\mathrm{B}$ and decreasing percentage of occupied antibonding states was found in the case of the TiZrNbTaMo alloys. ${ }^{63}$ However, for the CoCrFeNiX alloys with $4 d$ metals the behavior is surprisingly reversed, remarking that there is not always a clear correlation between the elastic properties and the simplified COHP analysis of the chemical bonding strength.

\section{CONCLUSIONS}

In this work, we have carried out a systematic first-principles study of the structure and properties of the multi-principal element alloys (MPEAs) from the CoCrFeNiX family for which experimental structures and some properties were already well studied, but the theoretical description was still lacking. The methodology employed here, which combines an evolutionary algorithm with energy calculations based on density functional theory, proves to be suitable for predicting the structure of these MPEAs with some restrictions. Namely, the experimental crystal structure (BCC or FCC) for single-phase alloys is well reproduced. For multi-phase alloys, we are able to find the crystal structure of the main solidsolution phase, except in the case of CoCrFeNiZr and $\mathrm{CoCrFeNiNb}$, for which the atomic mismatch parameter is the highest among all the alloys.

Within DFT-PBE, we have calculated and analyzed in detail the elastic as well as electronic properties of CoCrFeNiX MPEAs $\left(\mathrm{X}=\mathrm{Ti}, \mathrm{V}, \mathrm{Mn}, \mathrm{MnV}, \mathrm{Cu}, \mathrm{Zr}, \mathrm{Nb}, \mathrm{Mo}, \mathrm{Al}, \mathrm{Al}_{2}\right.$ ). Overall, our results for the elastic moduli are in good agreement with the existing experimental and theoretical data. According to our calculations, the elastic moduli of the studied CoCrFeNiX MPEAs are expected to be smaller than those of CoCrFeNi, except for the bulk moduli of the alloys with $\mathrm{Cu}, \mathrm{Mo}$, or $\mathrm{Nb}$.

Furthermore, our attempt to find a connection between the elastic properties of the alloys and their electronic structure (e.g., electronic density, density of states, and bonding character) has been partially successful. The spatial distribution of the electronic density can, for instance, explain the anisotropy of the elastic modulus exhibited by some of the alloys. As a general trend, our calculations for the alloys with partially filled $3 d$ and $4 d$ elements predict that the bulk, shear, and Young moduli increase with the occupation of the $d$-shell up to half-filling. The only exception to this observation is the bulk modulus of the $3 d$ CoCrFeNiX alloys, for which a decreasing value is instead observed. Interestingly, we find in this particular case that the bulk modulus correlates better with the bonding character of the occupied electronic states. More precisely, larger B values are found in the alloys with a smaller percentage of antibonding occupied electronic states. A similar bonding character analysis is, however, unable to explain the values of the bulk moduli for the $4 d \mathrm{CoCrFeNiX}$ alloys that are better understood in terms of the atomic radius mismatch parameter that characterizes the lattice distortion. Our analysis highlights that the elastic properties are, in the end, determined by various factors.

\section{SUPPLEMENTARY MATERIAL}

See the supplementary material for the total and partial density of states, as well as the direction-dependent Young's modulus for all the studied alloys.

\section{ACKNOWLEDGMENTS}

This work was partially financed by Gobierno Vasco through the ELKARTEK Project Nos. KK-2017/00007 and KK-2018/00015, the Spanish Ministerio de Economía, Industria y Competitividad Grant No. FIS2016-76471-P, and the Gobierno Vasco-UPV/EHU Project No. IT-1246-19.

\section{REFERENCES}

${ }^{\mathbf{1}}$ M. Beyramali Kivy, Y. Hong, and M. Asle Zaeem, Metals 9, 254 (2019).

${ }^{2}$ Y. Ikeda, B. Grabowski, and F. Körmann, Mater. Charact. 147, 464 (2019).

${ }^{3}$ Y. Zhang, T. T. Zuo, Z. Tang, M. C. Gao, K. A. Dahmen, P. K. Liaw, and Z. P. Lu, Prog. Mater. Sci. 61, 1 (2014).

${ }^{4}$ M.-H. Tsai and J.-W. Yeh, Mater. Res. Lett. 2, 107 (2014).

${ }^{5}$ E. J. Pickering and N. G. Jones, Int. Mater. Rev. 61, 183 (2016).

${ }^{6}$ D. Miracle and O. Senkov, Acta Mater. 122, 488 (2017).

${ }^{7}$ M. C. Gao, J.-W. Yeh, P. K. Liaw, and Y. Zhang, High-Entropy Alloys (Springer, 2016).

${ }^{\mathbf{8}}$ S. Gorsse, J.-P. Couzinié, and D. B. Miracle, C. R. Phys. 19, 721 (2018).

${ }^{9}$ S. Gorsse, M. Nguyen, O. Senkov, and D. Miracle, Data Brief 21, 2664 (2018).

${ }^{10}$ J.-W. Yeh, S.-K. Chen, S.-J. Lin, J.-Y. Gan, T.-S. Chin, T.-T. Shun, C.-H. Tsau, and S.-Y. Chang, Adv. Eng. Mater. 6, 299 (2004).

${ }^{11}$ B. Cantor, I. Chang, P. Knight, and A. Vincent, Mater. Sci. Eng. A 375-377, 213 (2004)

${ }^{12}$ C. Li, M. Zhao, J. C. Li, and Q. Jiang, J. Appl. Phys. 104, 113504 (2008).

${ }^{13}$ T.-T. Shun, L.-Y. Chang, and M.-H. Shiu, Mater. Sci. Eng. A 556, 170 (2012).

${ }^{14} \mathrm{X}$. Yang and Y. Zhang, Mater. Chem. Phys. 132, 233 (2012).

${ }^{15} \mathrm{~A}$. Gali and E. George, Intermetallics 39, 74 (2013).

${ }^{16}$ G. Salishchev, M. Tikhonovsky, D. Shaysultanov, N. Stepanov, A. Kuznetsov, I. Kolodiy, A. Tortika, and O. Senkov, J. Alloys Compd. 591, 11 (2014). 
${ }^{17}$ W. Liu, J. He, H. Huang, H. Wang, Z. Lu, and C. Liu, Intermetallics 60, 1 (2015).

${ }^{18}$ W. Liu, Z. Lu, J. He, J. Luan, Z. Wang, B. Liu, Y. Liu, M. Chen, and C. Liu, Acta Mater. 116, 332 (2016).

${ }^{19}$ U. Dahlborg, J. Cornide, M. Calvo-Dahlborg, T. Hansen, A. Fitch, Z. Leong, S. Chambreland, and R. Goodall, J. Alloys Compd. 681, 330 (2016).

${ }^{\mathbf{2 0}}$ A. Vida, L. K. Varga, N. Q. Chinh, D. Molnar, S. Huang, and L. Vitos, Mater. Sci. Eng. A 669, 14 (2016).

${ }^{21}$ G. Laplanche, U. F. Volkert, G. Eggeler, and E. P. George, Oxidat. Met. 85, 629 (2016).

${ }^{22}$ M. Laurent-Brocq, L. Perrière, R. Pirès, and Y. Champion, Mater. Des. 103, 84 (2016).

${ }^{23}$ S. R. Reddy, S. Bapari, P. P. Bhattacharjee, and A. H. Chokshi, Mater. Res. Lett. 5, 408 (2017).

${ }^{24}$ N. Park, B.-J. Lee, and N. Tsuji, J. Alloys Compd. 719, 189 (2017).

${ }^{25}$ W. Zhou, L. Fu, P. Liu, X. Xu, B. Chen, G. Zhu, X. Wang, A. Shan, and M. Chen, Intermetallics 85, 90 (2017).

${ }^{\mathbf{2 6}}$ S.-H. Joo, H. Kato, M. Jang, J. Moon, C. Tsai, J. Yeh, and H. Kim, Mater. Sci. Eng. A 689, 122 (2017).

${ }^{27}$ W. Huo, H. Zhou, F. Fang, X. Hu, Z. Xie, and J. Jiang, Mater. Sci. Eng. A 689, 366 (2017).

${ }^{28}$ H. Hadraba, Z. Chlup, A. Dlouhy, F. Dobes, P. Roupcova, M. Vilemova, and J. Matejicek, Mater. Sci. Eng. A 689, 252 (2017).

${ }^{29}$ M.-H. Tsai, A.-C. Fan, and H.-A. Wang, J. Alloys Compd. 695, 1479 (2017).

${ }^{30}$ S.-H. Joo, H. Kato, M. Jang, J. Moon, E. Kim, S.-J. Hong, and H. Kim, J. Alloys Compd. 698, 591 (2017).

${ }^{31}$ N. Eißmann, B. Klöden, T. Weißgärber, and B. Kieback, Powder Metall. 60, 184 (2017).

${ }^{32}$ W. Liu, T. Yang, and C. Liu, Mater. Chem. Phys. 210, 2-11 (2017).

${ }^{33}$ W. Kai, C. Li, F. Cheng, K. Chu, R. Huang, L. Tsay, and J. Kai, Corros. Sci. 121, 116 (2017)

${ }^{34}$ E. D. Tabachnikova, A. V. Podolskiy, M. O. Laktionova, N. A. Bereznaia, M. A. Tikhonovsky, and A. S. Tortika, J. Alloys Compd. 698, 501 (2017).

${ }^{35}$ H. Jiang, K. Han, D. Qiao, Y. Lu, Z. Cao, and T. Li, Mater. Chem. Phys. 210, 43-48 (2017).

${ }^{36}$ J. Wang, T. Guo, J. Li, W. Jia, and H. Kou, Mater. Chem. Phys. 210, 192-196 (2017).

37S. Xia, M. Gao, and Y. Zhang, Mater. Chem. Phys. 210, 213-221 (2017).

${ }^{38}$ M. Klimova, N. Stepanov, D. Shaysultanov, R. Chernichenko, N. Yurchenko, V. Sanin, and S. Zherebtsov, Materials 11, 53 (2018).

${ }^{39}$ M. Vaidya, K. Pradeep, B. Murty, G. Wilde, and S. Divinski, Acta Mater. 146, 211 (2018).

${ }^{40}$ W. Huo, H. Zhou, F. Fang, X. Zhou, Z. Xie, and J. Jiang, J. Alloys Compd. 735, 897 (2018)

${ }^{41}$ K. V. Yusenko, S. Riva, W. A. Crichton, K. Spektor, E. Bykova, A. Pakhomova, A. Tudball, I. Kupenko, A. Rohrbach, S. Klemme, F. Mazzali, S. Margadonna, N. P. Lavery, and S. G. Brown, J. Alloys Compd. 738, 491 (2018).

${ }^{42}$ W.-M. Choi, Y. H. Jo, S. S. Sohn, S. Lee, and B.-J. Lee, npj Comput. Mater. 4, 1 (2018).

${ }^{43}$ S. Zherebtsov, N. Stepanov, Y. Ivanisenko, D. Shaysultanov, N. Yurchenko, M. Klimova, and G. Salishchev, Metals 8, 123 (2018).

${ }^{44}$ O. N. Senkov, J. D. Miller, D. B. Miracle, and C. Woodward, Nat. Commun. 6 , 6529 (2015).

${ }^{45}$ C. Niu, A. Zaddach, C. Koch, and D. Irving, J. Alloys Compd. 672, 510 (2016).

${ }^{46} \mathrm{M}$. Ogura, T. Fukushima, R. Zeller, and P. H. Dederichs, J. Alloys Compd. 715, 454 (2017).

${ }^{47} \mathrm{H}$. Ge, H. Song, J. Shen, and F. Tian, Mater. Chem. Phys. 210, 320-326 (2017).

${ }^{48}$ S. Zhao, T. Egami, G. M. Stocks, and Y. Zhang, Phys. Rev. Mater. 2, 013602 (2018).

${ }^{49}$ F. Tian, L. Delczeg, N. Chen, L. K. Varga, J. Shen, and L. Vitos, Phys. Rev. B 88, 085128 (2013).

${ }^{\mathbf{5 0}}$ A. J. Zaddach, C. Niu, C. C. Koch, and D. L. Irving, JOM 65, 1780 (2013).
${ }^{\mathbf{5 1}}$ F. Tian, L. K. Varga, J. Shen, and L. Vitos, Comput. Mater. Sci. 111, 350 (2016).

${ }^{52}$ B. L. Gyorffy, Phys. Rev. B 5, 2382 (1972).

${ }^{53}$ P. Soven, Phys. Rev. 156, 809 (1967).

${ }^{54}$ A. Zunger, S.-H. Wei, L. G. Ferreira, and J. E. Bernard, Phys. Rev. Lett. 65, 353 (1990).

${ }^{55}$ S.-H. Wei, L. G. Ferreira, J. E. Bernard, and A. Zunger, Phys. Rev. B 42, 9622 (1990).

${ }^{\mathbf{5 6}}$ F. Tian, L. K. Varga, N. Chen, L. Delczeg, and L. Vitos, Phys. Rev. B 87, 075144 (2013).

${ }^{57}$ D. Ma, B. Grabowski, F. Körmann, J. Neugebauer, and D. Raabe, Acta Mater. 100, 90 (2015).

${ }^{58} \mathrm{X}$. Li, D. L. Irving, and L. Vitos, Sci. Rep. 8, 11196 (2018).

${ }^{59}$ A. R. Oganov and C. W. Glass, J. Chem. Phys. 124, 244704 (2006).

${ }^{60}$ A. R. Oganov, H. Stokes, and M. Valle, Acc. Chem. Res. 44, 227 (2011).

${ }^{61}$ A. O. Lyakhov, A. R. Oganov, H. Stokes, and Q. Zhu, Comp. Phys. Comm. 184, $1172(2013)$

${ }^{62}$ A. R. Oganov, Modern Methods of Crystal Structure Prediction (Wiley-VCH, Berlin, 2010)

${ }^{63}$ N. E. Koval, J. I. Juaristi, R. D. Muiño, and M. Alducin, Intermetallics 106, 130 (2019)

${ }^{64}$ E. Menou, I. Toda-Caraballo, P. E. J. R.-D. del Castillo, C. Pineau, E. Bertrand, G. Ramstein, and F. Tancret, Mater. Des. 143, 185 (2018).

${ }^{65} \mathrm{~K}$. Zhang and Z. Fu, Intermetallics 22, 24 (2012).

${ }^{66} \mathrm{~K}$. Zhang, Z. Fu, J. Zhang, W. Wang, H. Wang, Y. Wang, Q. Zhang, and J. Shi, Mater. Sci. Eng. A 508, 214 (2009).

${ }^{67}$ A. Haglund, M. Koehler, D. Catoor, E. George, and V. Keppens, Intermetallics 58, 62 (2015).

${ }^{68}$ N. Stepanov, D. Shaysultanov, G. Salishchev, M. Tikhonovsky, E. Oleynik, A. Tortika, and O. Senkov, J. Alloys Compd. 628, 170 (2015).

${ }^{69} \mathrm{G}$. Laplanche, P. Gadaud, O. Horst, F. Otto, G. Eggeler, and E. George, J. Alloys Compd. 623, 348 (2015).

${ }^{70} \mathrm{G}$. Bracq, M. Laurent-Brocq, L. Perrière, R. Pirès, J.-M. Joubert, and I. Guillot, Acta Mater. 128, 327 (2017).

${ }^{71}$ L. Zhang, P. Yu, M. Zhang, D. Liu, Z. Zhou, M. Ma, P. Liaw, G. Li, and R. Liu, Mater. Sci. Eng. A 707, 708 (2017).

${ }^{72}$ G. Muthupandi, K. R. Lim, Y. S. Na, J. Park, D. Lee, H. Kim, S. Park, and Y.-S. Choi, Mater. Sci. Eng. A 696, 146 (2017).

${ }^{73}$ S. Mohanty, T. Maity, S. Mukhopadhyay, S. Sarkar, N. Gurao, S. Bhowmick, and K. Biswas, Mater. Sci. Eng. A 679, 299 (2017).

${ }^{74}$ W. Huo, H. Zhou, F. Fang, Z. Xie, and J. Jiang, Mater. Des. 134, 226 (2017).

${ }^{75} \mathrm{G}$. Laplanche, P. Gadaud, C. Bärsch, K. Demtröder, C. Reinhart, J. Schreuer, and E. George, J. Alloys Compd. 746, 244 (2018).

${ }^{76} \mathrm{G}$. Kresse and J. Furthmüller, Phys. Rev. B 54, 11169 (1996).

${ }^{77} \mathrm{G}$. Kresse and J. Furthmüller, Comput. Mater. Sci. 6, 15 (1996).

78 J. P. Perdew, K. Burke, and M. Ernzerhof, Phys. Rev. Lett. 77, 3865 (1996).

${ }^{79}$ P. E. Blöchl, Phys. Rev. B 50, 17953 (1994).

${ }^{80}$ G. Kresse and D. Joubert, Phys. Rev. B 59, 1758 (1999).

${ }^{81}$ Y. Le Page and P. Saxe, Phys. Rev. B 65, 104104 (2002).

${ }^{82}$ C. Kittel, Introduction to Solid State Physics, 8th ed. (John Wiley \& Sons, Inc., New York, 2005), p. 50.

${ }^{83}$ N. W. Ashcroft and N. D. Mermin, Solid State Physics (Saunders College, Philadelphia, 1976)

${ }^{84}$ J. F. Nye, Physical Properties of Crystals (Oxford University Press, 1985).

${ }^{85}$ F. Tasnádi, M. Odén, and I. A. Abrikosov, Phys. Rev. B 85, 144112 (2012).

${ }^{86}$ M. C. Gao, Y. Suzuki, H. Schweiger, O. N. Doğan, J. Hawk, and M. Widom, J. Phys. Condens. Matter 25, 075402 (2013).

${ }^{87}$ W. Voigt, Lehrbuch der Kristallphysik (Taubner, Leipzig, 1928).

${ }^{88}$ A. Reuss, J. Appl. Math. Mech. 9, 49 (1929).

${ }^{89}$ K. W. Andrews, J. Phys. D Appl. Phys. 11, 2527 (1978).

${ }^{90} \mathrm{G}$. Grimvall, Thermophysical Properties of Materials (Elsevier Science B.V., Amsterdam, 1999).

${ }^{91}$ R. Hill, Proc. Phys. Soc. Sect. A 65, 349 (1952). 
${ }^{92} \mathrm{C}$. Zener, Elasticity and Anelasticity of Metals (University of Chicago Press, Chicago, Illinois, 1948).

${ }^{93}$ S. Guo and C. Liu, Prog. Nat. Sci. Mater. Int. 21, 433 (2011).

${ }^{94}$ M.-H. Tsai, J.-H. Li, A.-C. Fan, and P.-H. Tsai, Scr. Mater. 127, 6 (2017).

${ }^{95}$ B. Chanda and J. Das, Adv. Eng. Mater. 20, 1700908 (2018).

${ }^{96}$ O. Senkov and D. Miracle, J. Alloys Compd. 658, 603 (2016).

${ }^{97}$ S. Guo, C. Ng, J. Lu, and C. T. Liu, J. Appl. Phys. 109, 103505 (2011).

${ }^{98}$ W.-R. Wang, W.-L. Wang, S.-C. Wang, Y.-C. Tsai, C.-H. Lai, and J.-W. Yeh, Intermetallics 26, 44 (2012).

${ }^{99}$ X. Wang, Y. Zhang, Y. Qiao, and G. Chen, Intermetallics 15, 357 (2007).

${ }^{100}$ J. Cheng, X. Liang, and B. Xu, Surf. Coat. Technol. 240, 184 (2014).

${ }^{101}$ T.-T. Shun, L.-Y. Chang, and M.-H. Shiu, Mater. Charact. 70, 63 (2012).

${ }^{102}$ Y. Wang, Y. Yang, H. Yang, M. Zhang, S. Ma, and J. Qiao, Mater. Chem. Phys. 210, 233 (2018).

${ }^{103}$ E. K. Delczeg-Czirjak, E. Nurmi, K. Kokko, and L. Vitos, Phys. Rev. B 84, 094205 (2011).

${ }^{104}$ S. Pugh, Lond. Edinb. Dublin Philos. Mag. J. Sci. 45, 823 (1954).

${ }^{105}$ J. J. Lewandowski, W. H. Wang, and A. L. Greer, Philos. Mag. Lett. 85, 77 (2005).

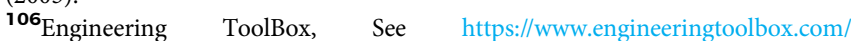
young-modulus-d_773.html for "Young's Modulus of Elasticity for Metals and Alloys," 2004 (accessed 11 April 2019).

${ }^{107}$ Z.-S. Nong, J.-C. Zhu, and R.-D. Zhao, Intermetallics 86, 134 (2017).

${ }^{108}$ E. J. Boyd and D. Uttamchandani, J. Microelectromech. Syst. 21, 243 (2012).

${ }^{109}$ U. Aydin, H. Titrian, and M. Friák, Self-Consistent Calculations - Elasticity of Multi-Phase Aggregates (Duesseldorf, Germany, 2012-2013).
${ }^{110^{H}}$. Titrian, U. Aydin, M. Friák, D. Ma, D. Raabe, and J. Neugebauer, MRS Proc. 1524, mrsf12-1524-rr06-03 (2013).

${ }^{11}$ M. Friák, W. A. Counts, D. Ma, B. Sander, D. Holec, D. Raabe, and J. Neugebauer, Materials 5, 1853 (2012).

${ }^{112}$ L.-F. Zhu, M. Friák, L. Lymperakis, H. Titrian, U. Aydin, A. Janus, H.-O. Fabritius, A. Ziegler, S. Nikolov, P. Hemzalová, D. Raabe, and J. Neugebauer, J. Mech. Behav. Biomed. Mater. 20, 296 (2013).

${ }^{113}$ I. Kireeva, Y. Chumlyakov, Z. Pobedennaya, I. Kuksgausen, and I. Karaman, Mater. Sci. Eng. A 705, 176 (2017).

${ }^{114}$ I. Kireeva, Y. Chumlyakov, Z. Pobedennaya, A. Vyrodova, and I. Karaman, Mater. Sci. Eng. A 713, 253 (2018).

${ }^{115}$ L. Tseng, J. Ma, S. Wang, I. Karaman, and Y. Chumlyakov, Scr. Mater. 116, 147 (2016).

${ }^{116}$ B. Uzer, S. Picak, J. Liu, T. Jozaghi, D. Canadinc, I. Karaman, Y. Chumlyakov, and I. Kireeva, Mater. Res. Lett. 6, 442 (2018).

${ }^{117}$ R. Dronskowski and P. E. Blöchl, J. Phys. Chem. 97, 8617 (1993).

${ }^{118}$ S. Maintz, V. L. Deringer, M. Esser, R. Nelson, A. Tchougréeff, and R. Dronskowski, Local Orbital Basis Suite Towards Electronic-Structure Reconstruction (Aachen, Germany, 2010-2017).

${ }^{119}$ V. L. Deringer, A. L. Tchougréeff, and R. Dronskowski, J. Phys. Chem. A 115, 5461 (2011).

${ }^{120}$ S. Maintz, V. L. Deringer, A. L. Tchougréeff, and R. Dronskowski, J. Comput. Chem. 34, 2557 (2013).

${ }^{121}$ S. Maintz, V. L. Deringer, A. L. Tchougréeff, and R. Dronskowski, J. Comput. Chem. 37, 1030 (2016). 